\title{
THE BOATMAN OF THE PADMA: AN EXISTENTIAL ELIXIR FOR THE POLITICS OF POVERTY
}

\author{
Dr. BidishaKantha ${ }^{1}$ \\ Designation: Asst. prof. of English, \\ Affiliation:St. Xavier's University Kolkata \\ Postal Address for sending: 29/ A lake east $4^{\text {th }}$ road, Santoshpur, Kolkata-700075

\section{Saumyadeep Bhattacharya ${ }^{2}$} \\ Designation: Asst. Prof. of English, \\ Affiliation: Govt. College Satwas, District: Dewas, Madhya Pradesh. \\ Postal Address for sending: 29/ A lake east $4^{\text {th }}$ road, Santoshpur, Kolkata-700075
}

\begin{abstract}
:
The Boatman of the Padma in its formulation far exceeds the genre of a novel and in its comparison to Hemingway's Old Man and the Sea has already established its property of being the upholder of human life in its truest colours. However the manner of narration which holds in its manner the Achebeesque performance of originality for the life of the marginal becomes its mouthpiece. While in his pursuit of a truthful representation the author brings out the politics that run in the society of the downtrodden simply at the cost of their existentialistic tendencies, deeply rooted not in the knowledge of spiritual crisis but in the pangs of hunger and the need for basic human dignity. In the skillful portrayal of his art Bandopadhyay has created a handbook for the perplexed in these situations doing justice to the intricacies of politics and oppression and thus providing a panacea for the woeful existence of the unwarranted.
\end{abstract} Keywords: subaltern, suppression, politics, poverty, ignorance.

The nation state of India with its multitude,variations has one reigning factor that brings the union of India together apart from the idealistic impressionism of the 'union' of states; it is the race for personal gains in the political game that runs the nation. Strong words though these may seem, the rise in political motivation for the functioning of the country in its daily treadmill has become an accepted reality, so much so that the element of surprise is inexistent and coherence and logical patterning of these problems hardly find explication in human thoughts. Within this lattice of the ever emerging gap between the commoners and the ones invested with power, fall the shadow of the penury stricken population who with their dilapidated eyes and bulging malnutrition 
VS Publications

Alford Council of International English \& Literature Journal(ACIELJ)

Impact Factor:4.401(SJIF)An International Peer-Reviewed English Journal

www.acielj.com

Vol-3,Issue-2,2020

ISSN:2581-6500

stare almost as if at an event with the enormousness of the motions of the universe, their sights, bereft of comprehension witness the routineroguery of which they are the subjects. These imps of ill fate and the harbingers of times worse being spoken of in multiple literatures and used in magnificent speeches by the worldly wise have a saga of their own.

A tale that should never be attempted interpretation at the hands of critics and their likes whose loaded words and jargonistic phrases cloud the view of the life that these waifs have suffered since ages. Them no law would save from soul piercing examination unlike the well guarded aboriginals of Andamans. Their lean body has hardly ever had the capacity to tolerate the pinch of a thousand knives digging deep, therefore they die a thousand times and in the process speak a thousand tales of poverty with each effort undertaken to evaluate the sheer cruelty that fate has inflicted upon them, never being considered by the lofty state machinery of which they are the unhealthy parts. ManikBandopadhyay, astalwart in Bengali literature by the merit of an insightfulcollection to his name opens avenues in understanding politics that poverty allows to be played on the lives of these helpless millions bringing in his subject group the communion of boatmen of the river Padmaand by successfully incorporating in his tale not a re rendition of the exact but rather making the exact happen once again in the corpus of his tale, he not only places before his audience an as you like it of the situation but at the same time focuses the light of intellect on the open wounds which are inflicted at a regular basis by all those who are ahead and above the station of these pitiable creatures as says SheguftaYasmin in claiming :"Padma Nadir Majhi is essentially a psycho anatomy dealing with the life and activities of the fishermen community surrounding the river Padma." (Yasmin 79).The Boatman ofthe Padma in this context does not remain merely a novel of substance but rises far above the domain of a literature of the oppressed, to claim for itself the title of being the mouthpiece of the marginal.

The very eloquence that Bandopadhyay gives tothis piece of literature might as well claim for itself a place in the shelf of the path breaking literary works especially in the realm of the subaltern. The consistent claim of the ability of the emancipated to talk of the oppressed being an ignominy upon the latter's condition is found at multiple junctures for example the claim:"Bandopadhyaya's knowledge of fisher communities are limited and are 'thin' compared with those of Barman."(Pokrant et al. 125) .This, however, seems irrelevant, as the narrator performs the brilliant task of taking an exemplary livelihood to reveal the stereotypical oppressive strategies operative in all similar domains, taking the tale further from being a handbook for the fishermen community alone. As a result, crude realismis made palpable to the extent that the dismal situation narrated affects the reader in a manner which is dependent on the sensitivity afforded by $\mathrm{him} / \mathrm{her}$. It therefore follows, that to a reader of dulled sensibilities the starkness 
VS Publications

Alford Council of International English \& Literature Journal(ACIELJ)

Impact Factor:4.401(SJIF)An International Peer-Reviewed English Journal

www.acielj.com

Vol-3,Issue-2,2020

ISSN:2581-6500

of neither the situation nor the resentment towards the machinery at work in causing the ultimate hopelessness might function to appear intolerable and potentially dystopic. On the other hand to a careful observer the forces at work, the manipulation in progress are to be well discerned making the author not only a pioneer in Bengali literature but marking him with a sight as keen as that of Achebe, whose daring presentation of Igbo culture in Things Fall Apart on a platter of originality gained international accolades.

The primary concern that throngs the life of most of the characters of the novel is the issue of survival, a fact which is undoubtedly of consequence to the teeming millions of a nation where the poverty line is well beneath the acceptable standards. Writing in the context of a period when the World War I had alreadytainted the face of the innocent world, the giving up of ideals of living to be replaced by the yearning to merely exist has become significant and the difficulty in acquiring this minimum means to survive had made its presence felt in the unforgiving human society. The crisis that arose among the knowledgeable populace was a tug at the roots of their religion encased spirituality compelling them to experience the horrid void within themselves; the sheer rootlessness of being. The concept of existing being linked with that of an evading knowledge of selfhood was disastrous, causing humongous turbulence in the domain of literature.

While the entire world hailed this new age literature as the mouthpiece of the human sorrows, the ones forgotten by the annals of the world to be counted as humans were fighting the existential crisis that they had hardly ever pondered upon through the million years of their beastly existence. With a regular war raging in stomachs and ravaging their entails, news of an external war doesn't appear in the novel. Hence a noted critic's allusion to war in this context, saying about the novel "It is mainly about the nature of human mind and the intricacies and meanness, which have entwined the human beings in the post war period"(Yasmin 79) might be considered erroneous. The existential crisis suffered by the fishermen of Padma was therefore entirely different, and indissolubly linked with the pangs of hunger that strung all their lives together in a wildly strewn mesh of trickery, treachery and deceit, " ManikBandopadhyay tells us that poverty creates chaos and subverts social values."(Casci 290)

This resounds at the end of the novel with a finality that causes the summation of all the loose ends of the prose, cements the defeat that had been looming throughout the prose.The simple mention of the fact that in one boat the choice of not eating food cooked by a Muslim was inconsiderable simply brushes aside the communal concerns that would otherwise seem important. The romantic tryst thatKuber seems to get entangled with Kapila, might appear as a welcome respite, a romantic relief to the glum portrait being painted otherwise; but on closer analysis the existence of a human being has besides the basic material requirement the sole other requirement of emotional sustenance, Kapila the daughter cast out by her in-laws, the otherwise oppressed in her wealthy household finds a 
VS Publications

Alford Council of International English \& Literature Journal(ACIELJ)

Impact Factor:4.401(SJIF)An International Peer-Reviewed English Journal

www.acielj.com

Vol-3,Issue-2,2020

ISSN:2581-6500

romantic mate in Kuber, who is deprived

of a suitable sentimentalliaison having an invalid wife with whom the only emotional attachment he shares seems to be at the level of listening to her stories with a childlike curiosity. The simple act of bringing him the tobacco he had left at home assumes importance as the invalid wife is unable to provide the camaraderie in visiting the place of work with an instrument that promises some respite in the hardwork that hardly guaranteed sustenance:

Since Mala had no mobility, it was within his own heart that Mala's confined and concentrated life had surged up and flourished: judged in the perspective of languishing on a narrow strip of bed under the broken thatch, the crippled Mala had no parallel in the world.But she could never come running to the riverbank to get him tobacco on a dark evening or stand erect in a defiant attitude like the twig of a bamboo.(Bandopadyay 63)

On the other hand, the instances of Rasu searching for the pretty bride in Gopi, which comes under sincere threat once Gopi too is rendered temporarily invalid opens new dimensions of thought. It goes without saying that the physical hunger is an undeniable entity in the lives of living organisms, however the essential point of departure while citing this instance in the text is the absence of the desire for emotional alliance in Rasu, whose sincerity is dictated by his physical urges which go unsatisfied in the absence of a proper livelihood. The memory of a lost household does not appear to haunt him apart from the initial days of his return when the act of reiterating the sorrows and evils faced by him seemed to have been the only elements that attributed temporary importance to him in the society of insignificants. Similarly the description of the great storm that arrives and simply takes away the lives of

Animuddi's wife and son, causes his house to be utterly destroyed followed by the moment he is guided to this harrowing reality on his arrival from his fishing expedition the next morning, are narrated with alacrity and in an unaffected narrative stance. The journalistic narration of the happening clearly saves any undue attention to be bestowed on any particular event in the novel,for when the community is of people living under the firmament of sorrow, paying heed to any such singular instance would be unduly. The point of view adopted towards all instances of sorrow and turmoil, grief and pitiable instances of small happiness with affected languor in the eloquence of a dragging recitation brings to the fore the normalcy of the incidents and their acceptable nature. In the words of Seely:

Bandopadhyay's narrative technique is effective in presenting neither a patronizing nor even a compassionate depiction of this lower economic stratum of village life.Instead, we are given an unemotional, accepting view of Kuber and his kind." (Seely 152)

The sensitive reader who in the process of living the novel searches for respite in the progression of the story finds 
VS Publications

Alford Council of International English \& Literature Journal(ACIELJ)

Impact Factor:4.401(SJIF)An International Peer-Reviewed English Journal

www.acielj.com

Vol-3,Issue-2,2020

ISSN:2581-6500

none and is cast into the abyss of a surer darkness that awaits at the end of the existential turmoil. However, what attracts the keen reader into the text further is not just the abject disillusion that is strewn throughout the text but the innate politics that simply work at levels difficult to fathom, so much so that the mouthpiece of the novel Kabir guides the reader through his knowledge of the venomous folds that he allows himself to be shrouded in before being punched into the jaws of death, all the while being aware of the end that awaited him. The foreboding the he had for the trade of Hossain, the reason he felt an innate fear were realized in the end in a climactic yet open ended manner leading to a continuation of the text beyond the last punctuation. The transfer of people to the animal infested Moynadwip by Hossain is the only instance that adds a "mysterious charm to the otherwise realistic fabric of the novel"(Mukhopadhyaya 144).

The opium trade that he indulged in and the impeccable behavior he forever possessed are but the implications of a person of perverted interests .His attempt at making his own island a success in terms of habitation and for the purpose of which he lured the helpless in his folds of gratitudinal servitude, smack of a politician. The need, that poverty incubates in these subjects of ill fate are the baits that come to the aid of individuals of intent much like Hossainmian. The abject poverty that these individuals live in, prevent their better senses from functioning. Their logic takes a set back until it is quite late. The reason for the duality portrayed in the entire community's having a foreboding about Hossainmian and at another point Kabir accepting his help for constructing his new rooms after the storm, reveals a situation of helplessness and utter need that can never be qualified as "greed". The following words encapsulate it all:

He weeps and thinks that he is poorer than the poor, lower kind of man than other lowers. Everyone takes him as granted and makes him fool and deprive like other religious and social rules. $\mathrm{He}$ knows everything, but can't protest because he has no right of that. (Yasmin 83)

The stealing of a fewannas at times from Hossainmian with the significant interference by the narratorial voice qualifying the petty theft as a bait that the cunning businessman used to keep him lured with, knowing well the work of conscience that work on the humble imply the tactful manipulation that they undergo, all for the necessity of survival.

. The need for money guides the essential commodities of life charting the domains of the physical and the emotional and in the process never shying from the petty crimes and deceitful sins that would otherwise not find existence in the minds of the men leading simple lives. Added to this is the sub plot of the lack of education, which invariably drives away Mejobabu who in his urge to do good visits the village folk at odd times trying to instill in them the tenets of decency and civilized living,and in the process is driven away 
VS Publications

Alford Council of International English \& Literature Journal(ACIELJ)

Impact Factor:4.401(SJIF)An International Peer-Reviewed English Journal

www.acielj.com

Vol-3,Issue-2 ,2020

ISSN:2581-6500

from them by the rumor mills run by the conservative domains.

The dual plane that the story is woven in observes a careful cause and effect relationship; delineating the cause which is poverty, the needs that it initiates and how the satiating of these needs is used as a bait for the wealthy and the influential forbidding the dismissal of the existential crisis suffered by the marginal,entrapping them in a vicious circle of exploitation and denigration. This being understood the open ended understanding of Kuber, causes significant confusion that ails the reader in judging whether the truth of the extra helpful shrewd politician was the truth Kuberhad unraveled about Hossainmian while coming to the conclusion that he had to do go Moynadwip else get arrested; or whether this was just a figment of imagination, a mirage witnessed by a distraught soul.

This indeed shrouds the truth of the character and the incident, making the reader spiral in a psychedelic ambiguity in case of a superficial understanding of the novel.However,on a greater level the reader is cast into the mould while witnessing the events happening in the tale and it is only on being cast out of it at the end of the story does the nature of the cast appear to him, a mould that is shaped by the fire of penury only to hold the interests of the mighty. The psychology of the poor that is deeply embedded throughout the novel posing deep insights into the nature and manner of their survival and the politics of poverty which come into play go hand in hand making the novel reveal the nuances of exploitation beneath the folds of poverty.

Therefore, making itself the philosopher's stone, that promises better understanding for the relief of emancipation.As is expressed passionately" ManikBandopadhyay said in their language that God exists in the good and gentle society, $\mathrm{He}$ is not found here in the fishermen community." (Yasmin 84), hence the wand of redemption lies in their own hands as the act of realization and not as empty prayers cast forth to the inexistent deity of infinite tolerance.

\section{References:}

[1]Bandopadhyay, Manik. The Boatman of the Padma.Trans.RatanK.Chattopadhy ay. New Delhi: Orient Black Swan, 2012. Print.

[2]Casci, Simonetta. "Natinalism and Gender Ideology in Bengali Literature."Il Politico 68.2 (1999): 277-91. Web. 25 Sept. 2016.

[3]Mukhopadhyaya, Arun Kumar. "ManikBandopadhyaya : A Novelist in Search of Life." Indian Literature 2nd ser. 16.1 (1973): 143-46. Web. 25 Sept. 2016.

[4]Pokrant, Bob, Peter Reeves, and John McGuire. "The Novelist's Image of South Asian Fishers: Exploring the Work of ManikBandopadhyaya,

[5]AdvaitaMalla Barman and ThakazhiSivasankaraPillai." South Asia: Journal of South Asian Studies 21.1 (2007): 123-38. Web. 24 Sept. 2016.

[5]Seely, Clinton."Padma River 
VS Publications

Alford Council of International English \& Literature Journal(ACIELJ)

Impact Factor:4.401(SJIF)An International Peer-Reviewed English Journal www.acielj.com

Boatman.By ManikBandopadhyay,

Translated by Barbara Painter and Yann Lovelock."Review.Journal of Asian Studies Nov. 1977: 152-53.

Jstor.org. Web. 25 Sept. 2016.

[6]Yasmin, Shegufta. "Struggle of Santiago and Kuber: A
Comparative Study between 'The Old Man and the Sea' and 'Padma Nadir Majhi." ASA University Review 6.1 (2012): 79-84. Web. 25 Sept. 2016. 